\title{
O SUPREMO TRIBUNAL FEDERAL E A ANENCEFALIA: UMA REFLEXÃO SOBRE A LEGITIMIDADE DEMOCRÁTICA DO JUDICIÁRIO À LUZ DE RAWLS, HABERMAS E NINO
}

\author{
THE FEDERAL SUPREME COURT AND ANENCEPHALY: A REFLECTION ON THE \\ DEMOCRATIC LEGITIMACY OF THE JUDICIARY IN LIGHT OF RAWLS, \\ HABERMAS AND NINO
}

\author{
MARIA EUGENIA BUNCHAFT ${ }^{1}$ \\ (UFSC / Brasil)
}

\begin{abstract}
RESUMO
O debate entre Habermas e Rawls representa uma contribuição fundamental para a compreensão das questões sobre reconhecimento, multiculturalismo e pós-secularismo, introduzindo diferentes concepções filosóficas que podem contribuir sobre a temática acerca do uso público da razão, a fim de elucidar as diferentes percepções teóricas capazes de atender aos desafios propostos pelas sociedades pluralistas. Carlos Santiago Nino, por sua vez, estabeleceu uma estratégia teórica denominada "construtivismo epistemológico", delineada a partir do debate Habermas-Rawls. Por conseguinte, pretendemos articular os fundamentos filosóficos atinentes à concepção de razão pública delineada por Rawls e Habermas e ao construtivismo epistemológico de Carlos Santiago Nino com a análise da legitimidade democrática do STF na resolução de uma questão moral controvertida que é objeto de um desacordo moral razoável: o aborto de fetos anencéfalos.
\end{abstract}

Palavras-chave: Habermas. Rawls. Nino. Razão pública. Ativismo judicial.

\begin{abstract}
The Habermas - Rawls debate represents a fundamental contribution to understanding the issues about recognition, multiculturalism and post-secularism by introducing different philosophical views that can contribute about the issue of the public use of reason in order to elucidate the different theoretical insights that can meet the challenges of pluralistic societies. Carlos Santiago Nino, in turn, established a strategy called "epistemological constructivism" outlined from Rawls-Habermas debate. Therefore, we intend to articulate the philosophical foundations relating to the Rawls's and Habermas's conceptions of public reason and Carlos Santiago Nino's epistemological constructivism with the analysis of democratic legitimacy of the Supreme Court to resolve a moral issue that is of a reasonable moral disagreement : the abortion of anencephalic fetuses.
\end{abstract}

Keywords: Habermas. Rawls. Nino. Public reason. Judicial activism. 


\section{Introdução}

O debate entre Habermas e Rawls representa uma contribuição fundamental para a compreensão do tema do reconhecimento, do multiculturalismo e do pós-secularismo, introduzindo diferentes concepções filosóficas que podem enriquecer em muito a temática acerca do uso público da razão, a fim de elucidar as diferentes percepções teóricas capazes de atender aos desafios propostos pelas sociedades pluralistas. Carlos Santiago Nino, por sua vez, estabeleceu uma estratégia teórica denominada "Construtivismo epistemológico", delineada a partir do debate Habermas-Rawls. Por conseguinte, pretendemos articular os fundamentos filosóficos atinentes à concepção de razão pública delineada por Rawls e Habermas e ao construtivismo epistemológico de Carlos Santiago Nino com a análise da legitimidade democrática do STF na resolução de uma questão moral controvertida que é objeto de um desacordo moral razoável: o aborto de fetos anencéfalos.

Nesse sentido, a possibilidade de articulação dos fundamentos filosóficos da teoria de Rawls, Nino e Habermas, assim como a integração do conceito de razão pública à cultura política brasileira, especialmente no que se refere à análise das consequências para a legitimidade democrática do STF, são fundamentais para o debate sobre a judicialização em temas delicados como anencefalia, transexualismo ou uniões homoafetivas. Para Rawls, a atuação do poder político em relação a questões constitucionais essenciais e de justiça básica somente ocorre por meio da fundamentação das decisões com base em princípios políticos que invocam os valores da razão pública. Nas palavras de Rawls,

\footnotetext{
nosso exercício do poder político é próprio e, por isso, justificável somente quando é exercido de acordo com uma Constituição cujos elementos essenciais se pode razoavelmente esperar que todos os cidadãos endossem, à luz de princípios e ideais aceitáveis para eles, enquanto razoáveis e racionais. ${ }^{2}$
}

Assim, Rawls desenvolve uma abordagem peculiar acerca do exercício do poder político, cuja legitimidade pressupõe o dever moral de justificação das decisões sobre questões constitucionais essenciais e de justiça básica à luz dos valores políticos da razão pública.

Mas a questão fundamental é: quais as implicações democráticas, sob o ponto de vista sociológico, da integração das concepções de razão pública delineadas por Habermas e Rawls ou do construtivismo epistemológico desenvolvido por Nino em relação a questões constitucionais 
controvertidas a serem julgadas pelo Judiciário tais como o aborto de fetos anencéfalos? $\mathrm{O}$ presente trabalho pretende investigar em que medida os referenciais teóricos dos referidos autores atendem aos desafios propostos por uma estratégia de legitimação do Supremo Tribunal Federal na decisão sobre a possibilidade de descriminalização da antecipação terapêutica da gestação de fetos anencéfalos ventilada na Argüição de Descumprimento de Preceito Fundamental n. 54/DF.

\section{O debate entre Habermas e Rawls}

De início, é premente lecionar que a tradição liberal enfatiza uma dimensão deontológica que estabelece princípios neutros de justiça como pressuposto para que os indivíduos escolham suas concepções de vida boa. Os autores comunitaristas, por sua vez, partem de uma crítica a filosofias universalistas, que estabelecem a prioridade do justo sobre aspectos relativos ao bem, ocultando singularidades culturais específicas em uma perspectiva homogeneizante. Tanto Habermas como Rawls rompem com a tradição comunitarista quando sustentam a inviabilidade de se adotar uma concepção de justiça comprometida com objetivos coletivos substantivos.

Diante dessa estrutura conceitual, o embate teórico entre Habermas e Rawls é um dos temas mais relevantes da filosofia política contemporânea, contemplando uma crítica de Habermas, uma réplica do segundo e um novo ensaio crítico do filósofo alemão. $\mathrm{O}$ debate surge em um número da revista The Journal of Philosophy, tendo como ponto de partida o ensaio crítico de Habermas, "Reconciliation through the public use of reason: remarks on John Rawls's Political Liberalism". Em verdade, tanto Habermas quanto Rawls distanciam-se de concepções comunitárias, pois delineiam uma concepção de justiça desvinculada de uma perspectiva apoiada em objetivos etnoculturais.

Nesse ponto, Habermas configura uma teoria da justiça que tem como pressuposto o estabelecimento de procedimentos por meio dos quais as reivindicações identitárias são tematizadas no espaço público, de forma a atender às demandas de uma sociedade plural. Diante dessa estrutura filosófica, a prioridade do justo sobre o bem traduz-se em uma concepção procedimental na qual o sistema de direitos institucionaliza as condições que garantem as autonomias pública e privada. Tal concepção é extremamente sofisticada, pois o autor procura desenvolver um ideal universalista com uma sensibilidade inclusiva em relação às diferenças 
culturais, uma vez que os princípios constitucionais passam a ser interpretados à luz de singularidades culturais específicas.

Nesse quadro teórico, Rawls, em O Liberalismo Político, estabelece um instrumental teórico destinado a analisar o fato do pluralismo razoável, ou seja, a existência de uma pluralidade de doutrinas abrangentes opostas e incompatíveis, porém razoáveis. Rawls delineia uma concepção política de justiça, pressupondo que os cidadãos que integram uma sociedade bem-ordenada, embora possuam concepções morais e filosóficas, são caracterizados pelos atributos da razoabilidade e da racionalidade. A ideia de posição original, delineada em Teoria da Justiça, é vinculada a uma filosofias contratualista desenvolvida com base em uma acordo hipotético em um contexto não histórico por meio do qual os cidadãos estabelecem uma concepção política de justiça, sendo desprovidos de suas concepções particulares de mundo. Os indivíduos não apenas ignoram o seu lugar no mundo, como também as contingência históricas e sociais.

Outrossim, com o intuito de estabelecer uma concepção política de justiça que irá pautar-se por princípios endossados por cidadãos razoáveis, Rawls recorre, em um segundo momento, ao conceito de consenso sobreposto. O consenso sobreposto irá inspirar a adesão por cidadãos racionais e razoáveis que, a despeito de suas doutrinas abrangentes, recorrem ao ideal da razão pública. A convergência de doutrinas abrangentes, porém razoáveis, é assegurada por meio do consenso sobreposto inerente a uma sociedade liberal. Por meio do consenso sobreposto, os cidadãos razoáveis endossam uma concepção política de justiça, recorrendo ao ideal da razão pública, que reflete valores de uma cultura política democrática. Essa concepção de justiça, que configura a melhor forma de concepção política, satisfaz os interesses de cidadãos livres e iguais.

Como se sabe, a ideia de consenso sobreposto pressupõe que as concepções políticas inerentes a doutrinas abrangentes deverão atender ao requisito da razoabilidade, articulando-se à concepção política de justiça. Nas palavras de Rawls, “as pessoas são razoáveis em um aspecto básico quando, entre iguais, por exemplo, estão dispostas a propor princípios e critérios como termos equitativos de cooperação e a submeter-se voluntariamente a eles, dada a garantia de que os outros farão o mesmo. "’ É mister elucidar que, para Rawls, a ideia da razão pública, portanto, funciona como um substrato legitimador das discussões fundamentais por meio das quais os cidadãos irão delinear uma concepção política de justiça. 
Com o intuito de elucidar a concepção de razão pública, assume especial relevância a distinção estabelecida por Rawls entre o ponto de vista público de perspectivas não públicas. De início, o autor pressupõe a existência de uma única razão pública e muitas razões não públicas, incluindo as autocompreensões morais das igrejas, universidades, sociedades científicas. Estas integram o horizonte de uma cultura de fundo de uma sociedade, incluindo as razões da sociedade civil, em contraposição à cultura política pública. Desse modo, os cidadãos poderiam fazer uso exclusivo de suas doutrinas abrangentes religiosas quando participam da "cultura de fundo", mas, devem submeter-se aos limites da razão pública quando participam da defesa política do espaço público. A discussão pública sobre questões políticas fundamentais deve atender ao requisito da razoabilidade, sendo esta necessária para a cooperação democrática em uma sociedade pluralista.

Com efeito, para Rawls, o fundamento de legitimidade das decisões sobre questões políticas fundamentais deve basear-se em razões que sejam publicamente aceitas por todos os cidadãos razoáveis. Rawls distingue a forma pela qual o ideal da razão pública aplica-se aos cidadãos e às autoridades estatais. Nas palavras de Rawls, "esse ideal aplica-se aos fóruns oficiais e, por isso, aos legisladores, quando falam no recinto do parlamento, e ao executivo, em seus atos

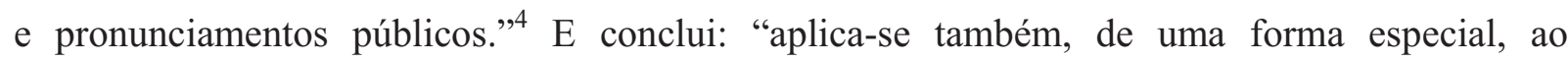
judiciário e, sobretudo, ao Supremo Tribunal numa democracia constitucional com controle da constitucionalidade das leis (revisão judicial)". 5

De fato, para o autor, o Tribunal Constitucional é um caso exemplar de razão pública, uma vez que os juízes devem explicar e justificar suas decisões de acordo com a melhor compreensão da Constituição, dos estatutos e precedentes. Para Rawls, "ao aplicar a razão pública, o tribunal deve evitar que a lei seja corroída pela legislação de maiorias transitórias ou, mas provavelmente, por interesses estreitos, organizados e bem posicionados, muito hábeis na obtenção do que querem.” A Suprema Corte deve sempre satisfazer ao ideal da razão pública, mesmo quando não estejam em jogo elementos constitucionais essenciais ou questões de justiça básica, diferentemente dos cidadãos e legisladores, que podem votar de acordo com suas doutrinas abrangentes nas questões que não envolvam os referidos elementos.

É por meio de uma dimensão restritiva imposta pela ideia de razão pública, que Rawls, no ensaio "The Idea of Public Reason Revisited" 7 , irá justificar o requisito da tradutibilidade, a fim de ajustar o exercício da manifestação das doutrinas religiosas na esfera pública a uma linguagem 
inerente aos pressupostos de valores políticos fundamentais. Ou seja, os cidadãos, ao participarem do fórum político público, com o intuito de deliberarem sobre questões constitucionais essenciais e de justiça básica, não possuem a obrigação de se desvincularem de doutrinas seculares ou religiosas, sendo possível a manifestação de doutrinas abrangentes na esfera pública. Não obstante, a ideia de razão pública, com o objetivo de administrar a pluralidade de doutrinas abrangentes que conformam uma sociedade pluralista, assume uma dimensão restritiva por meio da exigência da tradutibilidade, ou seja, requer a satisfação do pressuposto de traduzir argumentos não-públicos para uma linguagem que seja publicamente aceitável consoante valores políticos.

Não obstante, Habermas leciona que a teoria rawlsiana de justiça revela algumas insuficiências teóricas. Uma das críticas do filósofo alemão centra-se em torno da ideia de consenso sobreposto, uma vez que, para Rawls, este será o instrumento capaz de viabilizar a estabilidade social, tendo em vista a ideia de razoabilidade. Para Habermas, a teoria do autor americano pressupõe erroneamente que o teste da aceitabilidade de seus princípios conduziria à auto-estabilização da sociedade. O filósofo argumenta que a teoria rawlsiana apenas poderia ser utilizada como um mecanismo de aceitação, mas não de aceitabilidade. Habermas estabelece uma diferenciação entre procedimentos democráticos que garantem a estabilidade da ordem racional, tendo em vista a dimensão da aceitabilidade, das questões relativas à aceitação. $\mathrm{O}$ autor alemão alega ainda que a posição original contempla uma dimensão substantiva. Nessa perspectiva, se os interesses das partes são compreendidos como bens, ainda que estes se rearticulem e passem a ser compreendidos na forma de direitos, isso não anula o conteúdo substantivo dos princípios de justiça. Uma vez que os direitos básicos estão equiparados a bens, trata-se de uma ética substancialista que minimiza a sua pretensão deontológica. Ademais, Habermas critica a ideia de posição original de acordo com a qual, as partes desprovidas de suas contingências e particularidades estabelecem princípios de justiça, pois a ideia de privação de informações enfraquece o potencial de imparcialidade do procedimento de razão prática, impedindo processos de aprendizagem.

Em face dessa leitura, nas palavras de Habermas, “ pela limitação da informação, Rawls impõe uma perspectiva comum aos participantes da posição original e neutraliza assim de antemão, mediante um artifício, a multiplicidade das perspectivas particulares de interpretação. "» E conclui: "a ética do discurso, pelo contrário, vê o ponto de vista moral como encarnado no 
procedimento de uma argumentação levada a efeito intersubjetivamente, que exorta os participantes a erguerem as barreiras de suas perspectivas de interpretação. "9 $\mathrm{O}$ autor recorre aos postulados fundamentais da ética discursiva para contrapor seu modelo de comunidade ideal de fala à ideia de posição original.

Em suma, a posição original não seria suficientemente deliberativa, inviabilizando que os indivíduos, por meio de processos de aprendizagem, transcendam a si mesmos a partir de suas próprias concepções de bem. De um lado, a posição original não satisfaz plenamente a imparcialidade exigida pelos pressupostos deontológicos. De outro lado, ao atribuir primazia aos direitos liberais, em contraposição ao princípio democrático, Rawls não atinge seu objetivo de conciliar a liberdade dos modernos com a dos antigos, uma vez que sua teoria subordina o segundo princípio de justiça (igualdade) ao primeiro (liberdade). Habermas também demonstra-se cético em relação à renúncia rawlsiana à pretensão de verdade, uma vez que a sua própria concepção de razoabilidade é insuscetível de optar teoricamente entre aceitabilidade racional, visando a justiça e aceitação social voltada para a estabilidade. Nesse sentido, a concepção rawlsiana de razão pública não trabalha com os conceitos de verdade, pois resgata a ideia do politicamente razoável, tendo em vista o dever de civilidade e a ideia de cidadania democrática, pressupondo os princípios da tolerância e da liberdade de consciência.

No ensejo, Rawls inicia a sua réplica estabelecendo as diferenciações entre a sua teoria e a ética discursiva, tendo em vista os diferentes mecanismos de representação: a situação ideal de fala e a posição original. ${ }^{10}$ Aduz que a teoria da ação comunicativa, ao basear-se na ideia de situação ideal de fala, pretende dar conta da construção intersubjetiva da verdade e validade dos juízos morais. Nesse aspecto, Rawls argumenta que a ética discursiva e sua teoria da ação comunicativa pressupõem uma doutrina compreensiva, questionando o seu caráter procedimental. Diferentemente, a justiça como equidade, ao desvincular-se de doutrinas compreensivas, mantém intacta a sua dimensão procedimental e a prioridade do justo sobre o bem. O autor recorre a um equilíbrio reflexivo amplo por meio do qual a concepção de justiça, delineada na posição original, adequa-se às convicções e aos juízos mais profundos. Trata-se de um processo de ajustamento mútuo no qual os juízos e as convicções particulares ajustam-se à concepção de justiça e esta aos primeiros. De fato, a posição original representa um artifício por meio do qual as partes são desvinculadas de suas "doutrinas compreensivas" e convicções particulares de natureza moral, religiosa ou filosófica. Em Habermas, não é necessário esse 
artifício, porquanto a própria estrutura linguística permite um procedimento argumentativo sobre as concepções de bem.

Sob essa ótica, Rawls contra-argumenta no sentido de que o seu procedimentalismo não se confunde com aquele delineado por Habermas, tendo em vista sua distinção entre questões de justificação e de aplicabilidade. Uma justificação pública inerente à concepção política de justiça é sedimentada na multiplicidade de doutrinas abrangentes razoáveis, sendo intrínseca à cultura política das democracias contemporâneas. Todas aquelas doutrinas abrangentes que não satisfazem ao requisito da razoabilidade são insuscetíveis de formar a concepção política de justiça. Nesse sentido, sua concepção de estabilidade inerente ao consenso sobreposto seria um fator de justificação de concepções políticas e não apenas de equilíbrio entre doutrinas abrangentes conflitantes. Ademais, nega que sua teoria estabeleça uma concorrência entre as autonomias pública e privada, sustentando que a justiça como equidade, se corretamente interpretada, respeita a relevância e equilíbrio entre ambas as autonomias.

Diante dessa estrutura conceitual, outro ponto polêmico diz respeito à ideia de tradução. Nesse ponto, para Rawls, enquanto o requisito da tradução aplica-se de forma ampla em relação em relação à esfera pública formal, pode ser minimizado na esfera pública informal, com o intuito de permitir as manifestações religiosas. As doutrinas religiosas podem ser introduzidas na esfera pública informal, desde que atendam ao requisito da razoabilidade a da tradutibilidade. Entretanto, surge a questão: como encontrar justificativas seculares independentes de crenças particulares sem comprometer a integridade da identidade dos cidadãos enquanto crentes religiosos?

Assim, Habermas, no ensaio "Religião na Esfera Pública - Pressuposições Cognitivas para o Uso Público da Razão de Cidadãos Seculares e Religiosos", pondera que a ideia de razão pública delineada por Rawls é suscetível a críticas à medida que impõe uma sobrecarga cognitiva sobre cidadãos religiosos, porquanto muitos destes não poderiam empreender uma divisão artificial dentro de suas próprias mentes. Habermas assinala que a concepção rawlsiana de razão pública parte de uma perspectiva psicológica que, se não impede a introdução de doutrinas religiosas na esfera pública, sujeita-se a críticas relativas à exigência da tradutibilidade, que impõe aos cidadãos a tarefa de, quando se manifestarem no espaço público informal, empreenderem uma divisão artificial em suas mentes entre valores religiosos e políticos. Nas palavras de Habermas, "muitos cidadãos que se posicionam quanto a questões políticas, 
assumindo uma perspectiva religiosa, não têm nem conhecimentos suficientes para encontrar fundamentações seculares independentes de suas convicções autênticas". E conclui: "a pessoa piedosa encara sua existência a partir da fé. E fé verdadeira não é apenas doutrina, conteúdo no qual se crê, mas também fonte de energia da qual se alimenta a vida inteira do crente". ${ }^{11}$ Disso se infere, a nosso ver, que a conexão entre identidade religiosa e processos de aprendizagem, na ética discursiva, configura uma forma de preencher a lacuna teórica decorrente do modelo de razão pública delineado por John Rawls.

Nesse sentido, há uma tensão entre o reconhecimento da inclusão dos discursos religiosos na esfera pública e a exigência de que esta seja regulada pela razão natural. Habermas utiliza-se de duas estratégias para resolver esta tensão. De um lado, através da separação institucional entre religião e Estado; de outro lado, através da distinção entre esfera pública informal e a estrutura institucional do Estado, que inclui os parlamentos, ministérios e o Judiciário. Nesse ponto, a introdução de argumentos religiosos na esfera pública informal pressupõe processos de aprendizagem por meio dos quais tanto cidadãos religiosos como cidadãos seculares devem se engajar em uma autorreflexão crítica sobre suas crenças e concepções de bem. Tais processos de aprendizagem, inerentes a uma moral pós-convencional, permitem aos indivíduos confrontarem as autocompreensões de outros cidadãos com suas próprias doutrinas religiosas particulares, viabilizando a tradução de argumentos religiosos para argumentos publicamente aceitáveis na esfera pública, tendo em vista insights críticos e reflexivos.

Outrossim, não é possível saber de antemão se a proibição de manifestações religiosas na esfera pública informal estaria privando a sociedade de "recursos importantes para a criação de sentido", ou seja, de intuições morais possivelmente relevantes. E o trabalho de tradução pressupõe um esforço cooperativo do qual participam crentes e cidadãos não-religiosos, buscando-se um ponto de vista moral imparcial por meio da assunção recíproca de perspectivas. Portanto, o cidadão não religioso deve revelar-se aberto aos processos de aprendizagem estabelecidos por meio do diálogo com o concidadão religioso. No entanto, consideramos que tal alegação habermasiana, ao aplicar-se ao espaço público brasileiro, deve ser interpretada com uma certa cautela, no que se refere à discussão de direitos fundamentais de grupos minoritários que envolvam aspectos exclusivamente privados, ou seja, questões de moralidade autorreferente, tal como descreve Carlos Santiago Nino. Nesse quadro teórico, passamos a examinar o construtivismo epistemológico de Nino. 


\section{O Construtivismo Epistemológico de Carlos Santiago Nino}

De início, é premente lecionar que o construtivismo epistemológico, na obra de Nino, situa-se como uma posição intermediária entre as perspectivas de Rawls e Habermas, afirmando a centralidade de princípios morais, compreendidos como o substrato legitimador dos direitos humanos. Nino procura dialogar com ambas as vertentes filosóficas, ressalvando o caráter dialógico na formulação dos juízos morais, mas legitimando também a reflexão individual. Assim, em passagem elucidativa, sublinha que:

\footnotetext{
(...) quanto ao conhecimento da verdade moral, Rawls parece assumir que só é acessível através da reflexão individual, enquanto Habermas sustenta que somente a discussão coletiva é um método adequado para acessar princípios morais válidos. Acredito que a posição correta sobre ambas as questões é intermediária entre sustentadas por ambos os filósofos. (...) ${ }^{12}$
}

Com efeito, tanto Habermas como Nino ressalvam valor epistêmico da deliberação democrática para a resolução de desacordos morais, uma vez respeitadas as condições procedimentais do processo discursivo, suscitando um diálogo aberto e inclusivo no qual os interessados podem livremente confrontar seus argumentos. Resgatando ambas as matrizes epistemológicas, Nino leciona que, não obstante o processo deliberativo seja o método mais confiável para atingir princípios morais, tal compreensão não anula o fato de que a reflexão individual pode igualmente se configurar como um meio válido para alcançar princípios moralmente corretos sempre que a deliberação estiver desprovida de valor epistêmico. Nesse sentido, para Nino, em tese, o processo democrático, por seu valor epistêmico intrínseco, é o método mais confiável para se atingir princípios morais, em contraposição à reflexão individual monológica. Nas palavras de Nino,

\footnotetext{
Isto, sem embargo, não exclui a possibilidade de que, por meio da reflexão individual, se possa ter acesso ao conhecimento de soluções corretas, ainda que se admita ser este método muito menos confiável que o coletivo, devido à dificuldade de permanecer fiel à representação dos interesses dos outros e ser imparcial. ${ }^{13}$
}

É mister elucidar que, para o autor argentino, quando a deliberação estiver desprovida de valor epistêmico, a reflexão individual revelar-se-ia como um meio válido para resolução de questões morais controvertidas. Habermas, por sua vez, aposta no potencial racionalizador do 
debate a partir das contribuições dos próprios afetados, que se tornam autores e destinatários dos seus direitos, em contraposição a uma produção monológica de normas. Mas, em países periféricos de modernidade tardia, não podemos ignorar que, muitas vezes, há um déficit de representação de grupos minoritários no processo político majoritário, o que legitima a atuação do Poder Judiciário - identificado pelo autor como a expressão da reflexão individual - quando o processo deliberativo estiver desprovido de condições que configurem seu valor epistêmico.

Nesse particular, para Nino, as três dimensões fundamentais do constitucionalismo são: Democracia, reconhecimento de direitos e Constituição Histórica. Se o aspecto real do constitucionalismo constitui a Constituição Histórica, a Constituição ideal expressa-se nas ideias de Democracia e na dimensão dos direitos. Ademais, a legitimidade da "Constituição Histórica" tem como conteúdo o reconhecimento de princípios morais. Desse modo, o valor da autonomia moral é o elemento fundamental de qualquer processo discursivo e, com base nesta ideia, o autor refuta "qualquer política que imponha ideais pessoais sobre os indivíduos." ${ }^{14}$ Nino elucida que, em contraposição ao modelo liberal, "a visão perfeccionista recupera a adoção de um modelo de virtude pessoal definido por ideais cívicos e comunitários." 15

Nessa perspectiva, o autor estabelece três princípios básicos de uma concepção liberal de sociedade: o "princípio da inviolabilidade da pessoa humana", o "princípio da autonomia da pessoa humana" e o "princípio da dignidade da pessoa humana". O princípio da autonomia da pessoa relaciona-se ao valor da autonomia moral, sendo inadmissível qualquer forma de interferência externa sobre a escolha de ideais de excelência pessoal e virtude. O Estado deve manter-se neutro em relação aos projetos individuais de vida e ideais de excelência humana, contrapondo-se ao perfeccionismo.

Como se sabe, para o republicanismo, uma vez estimulada a participação política dos cidadãos, estes serão menos propensos a perseguir interesses privados, conectando democracia e o exercício das virtudes cívicas. Na perspectiva republicana, "o princípio da autonomia pessoal seria honrado se certas virtudes de caráter forem promovidas como um fim em si mesmas e não por seus méritos intrínsecos, mas como uma forma de obter ações que beneficiem ou evitem danos a outras pessoas. "16 $\mathrm{O}$ republicanismo parte do pressuposto segundo o qual a adoção de ideais de excelência articula-se a uma perspectiva comunitária, e não em uma esfera eminentemente privada. Nas palavras de Nino, "em contraste com o dogma do liberalismo, a 
visão perfeccionista recupera a adoção de um modelo de virtude pessoal definido por ideais cívicos e comunitários. "17

Não obstante, segundo o autor, embora autores republicanos pressuponham uma conexão entre democracia e virtudes cívicas, não podemos ignorar que determinadas ações individuais são insuscetíveis de ensejar efeitos negativos na esfera alheia, refutando teorias perfeccionistas que interfiram no princípio da autonomia pessoal. Nino parte de uma distinção entre uma moralidade pública, intersubjetiva, e uma moralidade privada, autorreferente ou pessoal. Esta consiste "naqueles ideais de excelência pessoal ou virtude, que valoram as ações em relação a seus efeitos sobre a qualidade de vida ou o caráter dos mesmos agentes." ${ }^{\text {"S }}$ Se o princípio da autonomia da pessoa atinge princípios intersubjetivos por meio dos quais julgamos as condutas dos indivíduos que afetam interesses alheios, é necessário limitar a autonomia de uns para preservar a de outros. No entanto, se o valor da autonomia contempla princípios morais autorreferentes, não há motivo para limitar uma esfera de autonomia pessoal, restringindo a eleição de ideais de excelência humana ou virtude pessoal, porque tais ideais não afetam a autonomia das demais pessoas.

A seu turno, o segundo princípio, denominado "princípio da inviolabilidade da pessoa", é um mecanismo capaz de resguardar interesses individuais contra demandas coletivas. $\mathrm{Na}$ sua primeira formulação, "o princípio da inviolabilidade da pessoa proíbe a diminuição da autonomia de uma pessoa para alcançar como único propósito o incremento da autonomia que gozam outros indivíduos." 19 O autor pretende, indubitavelmente, contrapor-se a concepções holísticas e coletivistas baseadas na " existência de uma entidade coletiva que constitui uma pessoa moral independente com interesses irredutíveis. " ${ }^{20} \mathrm{Ou}$ seja, o referido princípio veda a imposição de encargos e sacrifícios a certos indivíduos com o intuito de beneficiar a maioria da população. Trata-se de uma contraposição ao utilitarismo, que, para Rawls e Nino, desconhece a independência e a separabilidade das pessoas. Para o autor argentino, a articulação dos princípios da autonomia e da inviolabilidade da pessoa, entretanto, não constitui um referencial teórico suficiente para delinear uma concepção liberal de sociedade.

Em face desta leitura, refletindo sobre os limites teóricos dos referidos princípios, destaca que "o princípio da autonomia pessoal implica, paradoxalmente, uma supervisão permanente dos indivíduos para desqualificar qualquer decisão pessoal que restrinja sua própria autonomia, ainda quando o resultado obtido fora o incremento da autonomia de outras pessoas. "21 Pretendendo 
preencher tal lacuna teórica, o autor delineia o "princípio da dignidade da pessoa humana". Este princípio pressupõe as pessoas devem ser julgadas e tratadas exclusivamente com base em suas ações voluntárias e não segundo certos atributos e propriedades como raça, sexo, particularidades físicas ou classe social a que pertençam. Analisando o tema, Nino tece um dos mais lúcidos comentários a respeito do princípio da dignidade da pessoa, mencionando que:

\begin{abstract}
(...) O limite que o princípio da dignidade da pessoa estabelece em relação ao princípio da inviolabilidade da pessoa pode anular o limite que o último estabelece em relação ao princípio da autonomia da pessoa. Então, quando se aplica o princípio da dignidade da pessoa (já que a pessoa afetada consente em uma relação normativa resultante em uma perda de autonomia), a vedação à autonomia de um indivíduo, para incrementar a de outros, pode ser ignorada. Isto se manifesta no direito de que dispõem as instituições jurídicas de estabelecer obrigações e responsabilidade, dependendo do consentimento dos afetados - como ocorre nos casos de um contrato, o matrimônio e as leis penais deveria estar justificado sobre a base de promover a autonomia da sociedade em geral. $(\ldots)^{22}$
\end{abstract}

Disso se infere que, para Nino, a deliberação democrática nem sempre constitui o método mais confiável para adotar soluções moralmente corretas que interfiram nos ideais de excelência pessoal e projetos pessoais de vida. Nas palavras do autor, "os juízes não têm razões para subordinar seus juízos morais a uma lei democrática baseada em ideais pessoais de virtude ou excelência. Não existe nenhuma base epistêmica que justifique essa decisão. Neste ponto, somente o juízo dos indivíduos é relevante. "23 Em suma, a discussão democrática não possui valor epistêmico para impor ideais pessoais que violem o princípio da autonomia moral e, em consequência, qualquer juiz estaria legitimado para afastar a constitucionalidade de uma lei perfeccionista que imponha determinadas concepções de bem.

No ensejo, analisando o caso Bowers v. Hardwick ${ }^{24}$, no qual a Suprema Corte declarou a constitucionalidade de uma lei do Estado da Geórgia que proibia a conduta homossexual, o autor considera criticamente o posicionamento da mesma, tendo em vista a afirmação de argumentos perfeccionistas. Em síntese, alega ser papel do Judiciário declarar a inconstitucionalidade de uma legislação perfeccionista que imponha ideais de excelência. $\mathrm{O}$ autor estabelece uma distinção das questões de moralidade intersubjetiva, como, por exemplo, leis criminalizam o uso de droga para uso pessoal, das questões de moralidade autorreferente. Uma vez que lei protege dois bens jurídicos, objetivando também resguardar direitos de terceiras pessoas, seria legítimo que tal 
temática seja resolvida pelo processo político majoritário, pois não se trata de um ideal de excelência pessoal.

Sob esse aspecto, a ideia é investigar os motivos originários que deram ensejo à elaboração de determinadas leis, com o intuito de legitimar ou não o controle de constitucionalidade. Nas palavras de Nino, "se a proibição implica este último, ela só pode ser determinada pelo processo político ou corrigida por ele. Nesta situação, a proibição não deveria ser realizada pelo poder judicial, inclusive quando for incorreta. ",25 Indubitavelmente, é fundamental refletir sobre se a questão da criminalização da homofobia, do casamento gay, do transexualismo e do aborto de feto anencéfalos envolve um ideal de excelência pessoal ou um padrão moral intersubjetivo.

Diante do exposto, depreende-se que o direito ao casamento gay ou a pretensão de transexuais em realizar a adequação do prenome no registro civil, configuram uma moralidade autorreferente vinculada a ideais de excelência humana ou virtude pessoal, sem repercussão na autonomia das demais pessoas. Em contraposição, a questão atinente à criminalização da homofobia representa uma moralidade intersubjetiva, pois o valor da autonomia pessoal relativa à não-discriminação por orientação sexual afeta interesses alheios relativos à liberdade religiosa e de expressão de entidades religiosas, devendo ser regulada por um processo político democrático sensível às pretensões normativas que são racionalizadas no espaço público.

Sob essa ótica, a questão é relevante para a problemática da anencefalia, pois, se partirmos do pressuposto segundo o qual não há bem jurídico vida a ser tutelado, trata-se, portanto, de uma moralidade autorreferente. Feitas essas considerações, passo à análise da questão da anencefalia e da legitimidade democrática do STF.

\section{A questão da anencefalia no STF}

A anencefalia caracteriza-se como uma malformação congênita, estando os hemisférios cerebrais ausentes ou representados por massas pequenas que repousam na base. É uma alteração na formação cerebral, resultante de falha no mecanismo de fechamento do tubo neural. A questão da anencefalia chegou pela primeira vez ao STF em 26 de fevereiro de 2004, no Habeas Corpus 84025-6, impetrado por Gabriela de Oliveira Cordeiro, uma jovem de 19 anos que pretendia autorização judicial, objetivando realizar a antecipação terapêutica de parto de feto anencéfalo. 
Gabriela e seu marido procuraram a Defensoria Pública de Teresópolis e, em novembro de 2003, solicitaram a autorização, sendo esta indeferida na comarca de Teresópolis.

Sob esse prisma, em 7 de novembro, o recurso foi interposto ao Tribunal de Justiça, obtendo a autorização em 9 de novembro. Contra essa decisão, foi interposto um recurso por dois advogados, mas a relatora do recurso, Desembargadora Gizelda Leitão Teixeira, confirmou o seu entendimento anterior, concedendo a autorização para a antecipação; todavia, nesse momento, o Movimento Pró-vida da Igreja Católica já havia impetrado o remédio de Habeas Corpus no Supremo Tribunal de Justiça. A Ministra Laurita Vaz cassou liminarmente a autorização judicial que havia sido concedida anteriormente.

Nessa trajetória jurídica, em 26 de fevereiro de 2004, entretanto, um pedido de Habeas Corpus, em favor de Gabriela, foi impetrado no Supremo Tribunal Federal pelas Organizações não-governamentais Anis (Instituto de Bioética, Direitos Humanos e Gênero) e Themis (Assessoria Jurídica e Estudos de Gênero), com base no direito à saúde, à liberdade e à dignidade. Em 4 de março, foi iniciada a votação, tendo como relator o Min. Joaquim Barbosa. Não obstante, o pedido foi considerado prejudicado, pois, em sessão de julgamento, o Tribunal foi informado do fato de que o parto da gestante fora realizado, dando à luz a uma criança que veio a falecer alguns minutos após seu nascimento. Em decorrência, a ANIS e a THEMIS passaram a defender a tese de que o STF deveria solucionar o tema, razão pela qual foi interposta a ADPF $n^{\circ}$ 54. Mas, o voto do Min. J. Barbosa foi amplamente divulgado na mídia, sendo uma nítida expressão da sensibilidade do STF à temática da autonomia reprodutiva da mulher. Nesse quadro teórico, elucidativo o seguinte trecho do voto do Min. J. Barbosa:

\footnotetext{
(...) Nesse ponto, portanto, cumpre ressaltar que a procriação, a gestação, enfim, os direitos reprodutivos, são componentes indissociáveis do direito fundamental à liberdade e do princípio da autodeterminação pessoal, particularmente da mulher, razão por que, no presente caso, ainda com maior acerto, cumpre a esta Corte garantir seu legítimo exercício, nos limites ora esposados.

Lembro, invariavelmente, que essa concepção fundada no princípio da autonomia ou liberdade individual da mulher é a que tem prevalecido nas Cortes Constitucionais e Supremas que já se debruçaram sobre o tema $(\ldots)^{26}$
}

Nessa linha de raciocínio, tornar-se-á necessário postular que a problemática fundamental do debate teórico envolvido na questão da ADPF $\mathrm{n}{ }^{\circ} 54$ consiste, nas palavras do advogado e constitucionalista, Luis Roberto Barroso, "se ao declarar a não incidência do Código Penal a uma 
determinada situação, estaria o STF interpretando a Constituição - que é o seu papel - ou criando uma nova hipótese de não punibilidade do aborto, em invasão da competência do legislador. ${ }^{, 27} \mathrm{E}$ conclui: "Como se sabe, o Tribunal, por maioria, conheceu da ação, reconhecendo tratar-se de uma questão de interpretação constitucional e não de criação de direito novo." ${ }^{28}$ Em suma, de acordo com a doutrina, a interpretação conforme a Constituição pode implicar: a) uma delimitação do conteúdo da norma; b)sua não aplicação a um determinado contexto fático; c)a inconstitucionalidade de uma das normas decorrentes do texto, sendo que não há necessidade de uma declaração de inconstitucionalidade da norma, que permanece íntegra em ambas as situações.

Assim, o aborto provocado pela gestante ou por terceiro é tipificado nos artigos 124 a 126 do Código Penal. O aborto necessário, entretanto, indispensável para salvar a vida da gestante, não é punido, assim como o aborto no caso de gravidez resultante de estupro. Inexiste previsão, no artigo 128 do Código Penal, da possibilidade de antecipação terapêutica de parto decorrente da anencefalia, em razão do simples fato de que no momento histórico em que foi editado o Código Penal, os recursos tecnológicos eram escassos, inviabilizando o diagnóstico de anomalias fetais, tal como a anencefalia. Como sublinha o constitucionalista, "impor à mulher o dever de carregar por nove meses um feto que sabe, com plenitude de certeza, não sobreviverá, causando-lhe dor, angústia e frustração, importa violação de ambas as vertentes de sua dignidade humana". ${ }^{29}$ Nesse sentido, a denominada técnica de "interpretação conforme a Constituição", que tem sido desenvolvida pelo STF, ocorre quando, diante de uma variedade de métodos interpretativos, o Tribunal opta por uma linha de interpretação possível a respeito de uma norma legal, adequandoa a um determinado contexto fático.

É premente postular que, no caso da ADPF n. 54/DF, a tese proposta por Luis Roberto Barroso foi a de que o STF procedesse à interpretação conforme a Constituição de dispositivos do Código Penal relativos ao aborto, determinando a sua não incidência ao contexto fático em que a gestante de feto anencefálico opte voluntariamente pela interrupção terapêutica da gravidez. A ADPF $n^{\circ}$ 54/DF foi ajuizada pela Confederação Nacional dos Trabalhadores na Saúde, afirmando em nota prévia serem distintas as situações de antecipação terapêutica e a do aborto, tendo em vista que este pressupõe potencialidade de vida extrauterina do feto. Articula o envolvimento de preceitos fundamentais relativos à dignidade da pessoa humana, da legalidade, da liberdade e da autonomia da vontade, bem como o do direito à saúde. Sobre a inexistência de outro meio eficaz 
para viabilizar a antecipação terapêutica do parto, evoca o fato retratado no HC 84025-6, declarado prejudicado pelo Plenário.

Em vista disso, o autor requereu a suspensão do andamento de processos ou dos efeitos de decisões judiciais que tenham por objeto a aplicação de dispositivos do Código Penal na hipótese de antecipação terapêutica de parto de fetos anencéfalos, estabelecendo o direito constitucional da gestante de se submeter a procedimento que leve à interrupção da gravidez, desde que atestada a ocorrência da anomalia. Assim, o pedido final constitui a declaração de inconstitucionalidade, com eficácia abrangente e efeito vinculante da interpretação dos artigos 124, 126, e 128, I e II do Código Penal, como impeditiva da interpretação terapêutica de parto. Em $1^{\circ}$ de julho de 2004, o Min. Marco Aurélio de Mello concedeu o pedido liminar, reconhecendo o direito da gestante em optar pela antecipação terapêutica do parto, uma vez atestada a anencefalia por laudo médico. A liminar somente produziu efeitos por mais três meses, pois foi tornada sem efeito pelo Plenário do STF em 27 de abril de 2005, por sete votos a quatro; entretanto, igual votação admitiu que a ADPF fosse processada para que seu mérito fosse apreciado. Nesse momento, os Ministros Carlos Ayres de Britto, Gilmar Mendes, Sepúlveda Pertence e Nelson Jobim manifestaram-se no sentido de rejeitar a alegação de que seria incabível a propositura da ADPF, sendo vencidos os Ministros Eros Grau, Cesar Peluso e Ellen Gracie, que não conheceram da ação, tendo em vista que a mesma ofenderia a separação de poderes, criando uma nova hipótese de não punibilidade do aborto.

Diante dessa estrutura conceitual, trata-se de uma questão moralmente controvertida que envolve direitos de minoria (no caso, a gestante), mas a matéria não foi inteiramente regulada pelo processo político, legitimando uma inevitável expansão da atuação judicial. Ademais, a problemática jurídica enfrentada distingue-se da questão constitucional enfrentada em Roe vs. Wade. ${ }^{30}$ Nessa configuração normativa, analisando o tema, Eduardo Appio menciona que, no caso de aborto de feto anencefálico, a questão fundamental não é a proteção do direito à privacidade em confronto com o direito à vida, uma vez que, como alega a parte autora, inexiste qualquer possibilidade de vida da criança após o nascimento. Nesse ponto, é oportuno transcrever as explanações teóricas de Eduardo Appio: 
(...) Não existem, contudo, pontos de semelhança entre os casos Roe v. Wade e a ADPF 54, na medida em que o objeto central do debate em Roe foi a proteção da privacidade da mulher, assegurando-lhe um direito de escolha condicionado ao período de gestação. No caso do aborto de feto anencefálico, esta liberdade de escolha não está em jogo. Muito pelo contrário, os autores da ação alegam que em cem por cento dos casos não há possibilidade de sobrevida do feto fora do útero materno após encerrado o período da gestação. Portanto, enquanto em Roe v. Wade se buscava proteger um "direito de escolha" da mulher gestante, na ADPF 54 esse direito não existe, porque sequer se coloca a questão sobre a futura condição da mãe da mulher envolvida. Sabe-se, de antemão, que, não havendo sobrevida, não existe expectativa futura no tocante a esta condição e, portanto, não haverá limitação das opções futuras da mulher. (...) ${ }^{31}$

Indubitavelmente, a questão fundamental que é objeto de discussão na $\operatorname{ADPF} \mathrm{n}^{0} 54$, corresponde à proteção constitucional à saúde da gestante a ser tutelada pelo Estado, assim como sua integridade moral, tendo em vista a inexistência de uma estrutura cerebral própria que legitime a proteção estatal ao direito constitucional à vida do feto. Como assinala Eduardo Appio, "o que se encontra verdadeiramente em jogo é a integridade física e moral da gestante e, nesse sentido, o Estado tem o dever de assegurar um tratamento igual a todas as mulheres. "32 Assim como o autor, compreendemos que, se a questão fundamental a ser analisada é a integridade física e moral da gestante, inexistindo proteção constitucional ao direito à vida. Nesse ponto, o Supremo Tribunal Federal tem legitimidade para tutelar o direito fundamental à integridade física e moral da mulher, ainda que se adote uma perspectiva minimalista, não sendo necessário definir o momento em que a vida tem início, que é objeto de um desacordo moral razoável em uma sociedade pluralista.

Nessa abordagem constitucional, não há, portanto, necessidade de uma postura maximalista, com implicações futuras na discussão sobre o direito ao aborto no Brasil, podendo o STF ater-se aos limites específicos da demanda, resguardando a integridade física e moral de uma minoria sem invasão à competência do legislador. Se inexiste previsão, no artigo 128 do Código Penal, da possibilidade de antecipação terapêutica de parto decorrente da anencefalia, isso não exime o Estado de assegurar o direito à integridade física e moral da gestante de fetos anencefálico, sendo legítimo ao Judiciário declarar incidentalmente a inconstitucionalidade da referida lei, que estabelece tratamento diferenciado entre duas situações idênticas, em ofensa à isonomia. Compreendemos que, em um Estado pluralista, os fundamentos jurídicos utilizados para a análise da questão relativa ao aborto de fetos anencéfalos, devem estar pautados em argumentos de "razões públicas", e não por autocompreensões de mundo particulares, religiosas ou morais, insuscetíveis de legitimar a imposição estatal. A cada indivíduo deve ser assegurada 
uma esfera de autonomia moral que não pode ser instrumentalizada a um projeto político majoritário.

Nessa perspectiva, entretanto, não pretendemos legitimar, por exemplo, a atuação jurisdicional na proteção de uma esfera privada de gestantes de fetos anencéfalos e outras minorias como reflexo de teorias liberais que enfatizam o indivíduo atomizado, mas apenas de ressaltar que, quando maiorias parlamentares impõem doutrinas abrangentes, frustrando o debate, o Judiciário dispõe de legitimidade para proteger direitos fundamentais de minorias em uma dimensão substancialista, corrigindo os desvios do procedimento. Um exemplo da ausência de valor epistêmico do processo deliberativo na regulamentação de direitos de minorias são os diversos projetos de lei que tentavam tratar da antecipação terapêutica da gestação de fetos anencéfalos. Os Projetos de Lei $n^{\circ} 4.403 / 04$, que inseria um inciso ao artigo 128 do Código Penal, e $n^{\circ} 4360 / 04$ tentavam regulamentar a matéria, mas foram arquivados. Em 14 de Agosto de 2007, o deputado Pinotti apresentou requerimento de desarquivamento do Projeto de Lei $\mathrm{n}^{\circ}$ 4.360/04, mas foi indeferido em 21 de Agosto. Em relação ao projeto ${ }^{\circ}{ }^{4} 4.403 / 04$, foi solicitado o desarquivamento em 2007, tendo a tramitação sido retomada na Comissão de Constituição e Justiça e de Cidadania da Câmara. Há o Projeto de Lei $n^{\circ} 183$ de 2004, que é de autoria do Senador Duciomar Costa, pretendendo modificar o artigo 128 do Código Penal, para inserir o aborto de feto anencéfalo, sendo objeto de análise na Comissão de Constituição e Justiça do Senado no momento de elaboração do presente artigo.

Nesse quadro teórico, tais exemplos demonstram que, em uma sociedade como a brasileira, de população majoritariamente católica, a ideia habermasiana de um debate público franco e aberto - capaz de inspirar processos de aprendizagem entre cidadãos religiosos e concidadãos que professam doutrinas seculares - encontra-se distante da realidade fática, devendo ser analisada com a devida cautela em questões de moralidade autorreferente. Ademais, é patente também que o processo político majoritário não regulamenta adequadamente a questão em virtude de uma ausência de valor epistêmico em razão da qual as condições de abertura e participação dos afetados não estão presentes. Na prática, os sistemas partidários formam lobbies que atuam segundo acordos estratégicos no exercício do poder político. Esta descaracterização do uso público da razão na instância deliberativa legitima a reflexão individual exercida pelo Poder Judiciário nas questões de moralidade autorreferente. Defendemos que o STF - enquanto instância de representação de minorias - também pode funcionar como um fórum da razão 
pública capaz de resguardar uma esfera de moralidade autorreferente, sempre que as instâncias deliberativas não forem sensíveis a expectativas normativas relativas a determinadas minorias, tais como gestantes de fetos anencéfalos.

\section{Conclusão}

O conceito de razão pública assume especial relevância nas sociedades contemporâneas, que têm como elemento incontornável a existência do denominado desacordo moral razoável acerca de concepções de vida digna, tendo em vista a inexistência de uma consenso substantivo sobre valores. Em um contexto marcado pelo pluralismo, o conceito de razão pública tem como aspecto fundamental a necessidade de justificação das decisões políticas, tanto na esfera legislativa, como na judicial, com base em valores que sejam publicamente aceitos por cidadãos.

Indubitavelmente, o voto do Min. Joaquim Barbosa foi capaz de demonstrar a independência do direito, revelando como arena constitucional - enquanto cenário simbólico de lutas pelo reconhecimento - tem potencialidade em conectar autonomia judicial e legitimidade democrática, com base em argumentos fundamentados em "razões públicas". Tal decisão demonstra como juízes podem usar princípios constitucionais de abertura argumentativa para mediar o conflito e o diálogo público sobre pretensões normativas vinculadas a direitos de minorias. Nesse ponto, se a deliberação democrática falhar, no que se refere, ao ideal de neutralidade, tendo em vista a possibilidade fática de que maiorias parlamentares imponham concepções abrangentes que frustram o debate, descaracteriza-se o uso público da razão e o valor epistêmico do processo democrático, legitimando-se a expansão da atividade judicial.

Outrossim, percebemos, com base em Nino, que a reflexão judicial também representa um meio moralmente válido de resolução do desacordo moral razoável, sempre que, descaracterizado o uso público da razão e o valor epistêmico do processo democrático, seja pela imposição de doutrinas religiosas abrangentes que violam direitos de minorias, seja pela ausência de abertura e participação dos afetados no processo político. Diante do exposto, depreende-se que, no caso da anencefalia, a questão fundamental constitui a integridade física e moral da gestante, sem implicações na esfera jurídica alheia, devendo ser considerada não como uma moralidade intersubjetiva, mas como uma moralidade autorreferente, tendo em vista a ausência de viabilidade de vida. A questão fundamental a ser considerada não é o direito à privacidade da 
gestante em face do direito à vida do feto, mas o direito à saúde e à integridade moral da gestante, buscando alcançar um tratamento isonômico na aplicação da lei penal. 


\section{Notas}

${ }^{1}$ Doutora e Mestre em Teoria do Estado e Direito Constitucional pela PUC-Rio. Pós-doutoranda em Filosofia na UFSC, com bolsa REUNI. Autora do livro "O Patriotismo Constitucional na perspectiva de Jürgen Habermas", Ed. Lumen Juris, 2010. Professora e Pesquisadora do Unifoa-Centro Universitário de Volta Redonda.

${ }^{2}$ RAWLS, John. O Liberalismo Político. São Paulo: Ática, 2000, p. 266.

${ }^{3}$ Ibidem, p. 93.

${ }^{4}$ Ibidem, p. 264.

${ }^{5}$ Ibidem, p. 264.

${ }^{6}$ Ibidem, p. 264

${ }^{7}$ RAWLS, John. "The Idea of Public Reason Revisited". In: Collected Papers. Cambridge: Harvard University Press, 1999. Neste ensaio, Rawls irá estabelecer algumas modificações na ideia de razão pública delineada na sexta conferência da edição de 1993 Political Liberalism.

${ }^{8}$ HABERMAS, Jürgen. "Reconciliación mediante el uso público de la razón”. In: HABERMAS, Jürgen; RAWLS, John. Debate sobre el Liberalismo Político. Barcelona: Paidós, 1998, p. 53.

${ }^{9}$ Ibidem, p. 53.

${ }^{10}$ RAWLS, John. "Réplica a Habermas". In: HABERMAS, Jürgen; RAWLS, John. Debate sobre el Liberalismo Político. Barcelona: Paidós, 1998.

${ }^{11}$ HABERMAS, Jürgen. "Religião na Esfera Pública. Pressuposições Cognitivas para o Uso Público da Razão de Cidadãos Seculares e Religiosos". In: HABERMAS, Jürgen. Entre Naturalismo e Religião - Estudos Filosóficos. Rio de Janeiro: Tempo Brasileiro, 2007, p. 144.

${ }^{12}$ NINO, Santiago. El Constructivismo Ético. Madrid: Centro de Estudios Constitucionales, 1989, p. 14.

${ }^{13}$ NINO, Santiago. La Constitución de la democracia deliberativa. Barcelona: Gedisa, 1997, p. 161.

${ }^{14}$ NINO, Santiago. La Constitución de la democracia deliberativa. Barcelona: Gedisa, 1997, p. 278.

${ }^{15}$ Ibidem, p. 140.

${ }^{16}$ Ibidem, p. 141.

${ }^{17}$ Ibidem, p. 140.

${ }^{18}$ Ibidem, p. 278.

${ }^{19}$ Ibidem, p. 79.

${ }^{20}$ Ibidem, p. 79.

${ }^{21}$ Ibidem, p. 80 .

${ }^{22}$ Ibidem, p. 80-81.

${ }^{23}$ Ibidem, p. 278.

ethic@-Florianópolis, v. 10, n. 3, p. 55 -82, Dez. 2011. 
${ }^{24}$ Bowers v. Hardwick. 478 U. S 186 (1986).

${ }^{25}$ Ibidem, p. 279-280.

${ }^{26}$ STF, HC n. 84025-6. Voto do Min. Joaquim Barbosa.

${ }^{27}$ BARROSO, Luis Roberto. "Gestação de Fetos Anencefálicos e Pesquisas com Células-tronco: dois temas acerca da vida e da dignidade na Constituição". In: SARMENTO, Daniel e GALDINO, Flavio (orgs. ). Direitos Fundamentais - Estudos em Homenagem ao Professor Ricardo Lobo Torres. Rio de Janeiro: Renovar, 2006, p. 700.

${ }^{28}$ Ibidem, p. 701.

${ }^{29}$ Ibidem, p. 684 .

${ }^{30}$ Roe v. Wade. 410 U.S. 113 (1973).

${ }^{31}$ Roe v. Wade. 410 U.S. 113 (1973).

${ }^{32}$ APPIO, Eduardo. Direito das Minorias. São Paulo: Revista dos Tribunais, 2009, p. 358. 


\section{Referências Bibliográficas}

APPIO, Eduardo (2009). Direito das Minorias. São Paulo: Revista dos Tribunais.

AUDI, R. (1993): “The Place of Religious Argument in a Free and Democratic Society". San Diego Law Review, v. 30, n. 4, 677-702.

— (2000): Religious Commitment and Secular Reason. Cambridge: Cambridge University Press.

BARRY, B. (2001): Culture and Equality: An Egalitarian Critique of Multiculturalism. Cambridge (Mass.): Harvard University Press.

BARROSO, Luis Roberto (2006):“Gestação de Fetos Anencefálicos e Pesquisas com Célulastronco: dois temas acerca da vida e da dignidade na Constituição”. In: SARMENTO, Daniel e GALDINO, Flavio (orgs. ). Direitos Fundamentais - Estudos em Homenagem ao Professor Ricardo Lobo Torres. Rio de Janeiro: Renovar.

BAYNES, K. (1992): The Normative Grounds of Social Criticism: Kant, Rawls and Habermas. Albany, State University of New York Press.

BAYNES, K. and VON SCHOMBERG, R. (eds.) (2002): Discourse and Democracy: Essays on Habermas's Between Facts and Norms. Albany, State University of New York Press.

BENHABIB, S. (2002): The Claims of Culture: Equality and Diversity in the Global Era. Princeton: Princeton University Press.

BENHABIB, S. (ed.) (1996): Democracy and Difference: Contesting the Boundaries of the Political. Princeton: Princeton University Press.

BERGER, P. (ed.) (1999): The Desecularization of the World: Resurgent Religion and World Politics. Washington: Ethics and Public Policy Center.

BROWNING, D. and SCHÜSSLER FIORENZA, F. (eds.) (1992): Habermas, Modernity, and Public Theology. New York: Crossroad Publishers.

COOKE, M. (1997): "Authenticity and Autonomy: Taylor, Habermas, and the Politics of Recognition". Political Theory, v. 25, n. 2, 258-288.

— (2000): "Five Arguments for Deliberative Democracy", Political Studies, v. 48, n. 5, 947-969.

- (2006): "Salvaging and Secularizing the Semantic Contents of Religion: The Limitations of Habermas's Postmetaphysical Proposal," International Journal of the Philosophy of Religion, v. 60, ns. 1-3, 187-207. 
- (2007): "A Secular State for a Postsecular Society? Postmetaphysical Political Theory and the Place of Religion". Constellations, v. 14, n. 2, 224-238.

CUNEO, T. (ed.) (2004): Religion in the Liberal Polity. Notre Dame: University of Notre Dame Press.

DOMBROWSKI, D. (2001): Rawls and Religion: The Case for Political Liberalism. Albany: State University of New York Press.

DWORKIN, R. (2000): Sovereign Virtue: The Theory and Practice of Equality. Cambridge (Mass.): Harvard University Press.

ESTLUND, D. (1998): "The Insularity of the Reasonable: Why Political Liberalism Must Admit the Truth". Ethics, v. 108, 252-275.

FACHIN, Luiz Edson (1997): “Aspectos Jurídicos da União de Pessoas do Mesmo Sexo”. In: $A$ nova família: problemas e perspectivas. Rio de Janeiro: Renovar.

FRASER, N. (1997): Justice Interruptus: Critical Reflections on the Postsocialist Condition. London: Routledge.

FRASER, N. and HONNETH, A. (2003): Redistribution or Recognition? A Political-Philosophical Exchange. London: Verso.

FREEMAN, S. (2006): Justice and the Social Contract: Essays on Rawlsian Political Philosophy. Oxford: Oxford University Press.

— (2007): Rawls (Routledge Philosophers). London: Routledge.

FREEMAN, S. (ed.) (2002): The Cambridge Companion to Rawls. Cambridge: Cambridge University Press.

GUTMANN, A. (ed.) (1994): Multiculturalism: Examining the Politics of Recognition. Princeton: Princeton University Press.

- (2004): Identity in Democracy. Princeton: Princeton University Press.

HABERMAS, J. (1997): Direito e Democracia: entre facticidade e validade. Rio de Janeiro: Tempo Brasileiro [Faktizität und Geltung. Beiträge zur Diskurstheorie des Rechts und des democratischen Rechtsstaats. Frankfurt: Suhrkamp, 1992].

- (1998a): The Inclusion of the Other: Studies in Political Theory. Cambridge (Mass.): MIT Press [Die Einbeziehung des Anderen. Studien zur politischen Theorie. Frankfurt: Suhrkamp, 1996].

- (1998b)HABERMAS, Jürgen. "Reconciliación mediante el uso público de la razón”. In: HABERMAS, Jürgen; RAWLS, John. Debate sobre el Liberalismo Político. Barcelona: Paidós. 
- (2001a): A Constelação Pós-Nacional: Ensaios Políticos. São Paulo: Littera Mundi, 2001 [Die postnationale Konstellation. Politische Essays. Frankfurt: Suhrkamp, 1998].

- (2001b): Kommunikatives Handeln und detranszendentalisierte Vernunft. Stuttgart, Reclam Verlag [in: 2007].

- (2002a): Religion and Rationality: Essays on Reason, God, and Modernity (edited by Eduardo Mendieta). Cambridge (Mass.): MIT Press.

— (2002b): Glauben und Wissen. Frankfurt: Suhrkamp [in: 2004b].

- (2003): Era das Transições. Rio de Janeiro: Tempo Brasileiro [Zeit der Übergänge. Kleine politische Schriften IX. Frankfurt: Suhrkamp, 2001].

- (2004a): Verdade e Justificação: Ensaios Filosóficos. São Paulo: Edições Loyola [Wahrheit und Rechtfertigung. Philosophische Aufsätze. Frankfurt: Suhrkamp, 1999].

- (2004b): O Futuro da Natureza Humana: a caminho de uma eugenia liberal? São Paulo: Martins Fontes [Die Zukunft der menschlichen Natur. Auf dem Weg zu einer liberalen Eugenik? Frankfurt: Suhrkamp, 2001]

- (2006a): O Ocidente Dividido. Rio de Janeiro: Tempo Brasileiro [Der gespaltene Westen. Kleine politische Schriften X. Frankfurt: Suhrkamp, 2004].

- (2006b): The Dialectics of Secularization: On Reason and Religion (with Joseph Ratzinger; edited by Florian Schuller). San Francisco: Ignatius Press, 2006 [Dialektik der Säkularisierung. Über Vernunft und Religion. Vienna: Herder Verlag, 2005; in: 2007].

- (2007): Entre Naturalismo e Religião: Estudos Filosóficos. Rio de Janeiro: Tempo Brasileiro [Zwischen Naturalismus und Religion. Philosophische Aufsätze. Frankfurt: Suhrkamp, 2005].

HARRINGTON, A. (2007): "Habermas and the Post-Secular Society". European Journal of Social Theory, v. 10, n. 4, 543-560.

— (2007): "Habermas's Theological Turn?" Journal for the Theory of Social Behaviour, v. 37, n. $1,45-61$.

HELD, D. (1996): Models of Democracy. Stanford: Stanford University Press.

HEYD, D. (1996): Toleration: An Elusive Virtue. Princeton: Princeton University Press.

LAFONT, C. (2003): Procedural justice? Implications of the Rawls-Habermas Debate for Discourse Ethics". Philosophy and Social Criticism, v. 29, n. 2, 163-181. 
- (2007): "Religion in the Public Sphere: Remarks on Habermas's Conception of Public Deliberation in Postsecular Societies". Constellations, v. 14, n. 2, 239-259.

MACEDO, S. (ed.) (1999): Deliberative Politics: Essays on Democracy and Disagreement. Oxford: Oxford University Press.

McKINNON, C. and CASTIGLIONE, D. (eds.) (2003): The Culture of Toleration in Diverse Societies: Reasonable Tolerance. Manchester: Manchester University Press.

NINO, Santiago. (1989): El Constructivismo Ético. Madrid: Centro de Estudios Constitucionales.

— (1992): Los Fundamentos Del Derecho Constitucional. Buenos Aires: Astraa.

— (1997): La Constitución de la democracia deliberativa Barcelona: Gedisa.

NORRIS, P. and INGLEHART, R. (2004): Sacred and Secular: Religion and Politics Worldwide. Cambridge: Cambridge University Press.

PERES, A. P. (2001): Transexualismo - O Direito a uma Identidade Sexual. Rio de Janeiro: Renovar.

PERRY, M. (1999): Religion in Politics: Constitutional and Moral Perspectives. Oxford: Oxford University Press.

- (2003): Under God? Religious Faith and Liberal Democracy. Cambridge: Cambridge University Press.

RAWLS, J. (1996): Political Liberalism (paperback edition with a new introduction). New York: Columbia University Press.

- (1998): "Réplica a Habermas". In: HABERMAS, Jürgen; RAWLS, John. Debate sobre el Liberalismo Político. Barcelona: Paidós.

- (1999a): The Law of Peoples; with "The Idea of Public Reason Revisited". Cambridge (Mass.): Harvard University Press.

- (1999b): Collected Papers (edited by Samuel Freeman). Cambridge (Mass.): Harvard University Press.

- (2000a): Lectures on the history of moral philosophy (edited by Barbara Herman). Cambridge (Mass.): Harvard University Press.

- (2000b): O Liberalismo Político. São Paulo: Ática. 
- (2001): Justice as Fairness: A Restatement (edited by Erin Kelly). Cambridge (Mass.): Harvard University Press.

- (2007): Lectures on the history of political philosophy (edited by Samuel Freeman). Cambridge (Mass.): Harvard University Press.

RAZ, J. (1994): Ethics in the Public Domain. Oxford: Clarendon Press.

- (1999): Engaging Reason: On the Theory of Value and Action. Oxford: Oxford University Press. 